\title{
Understanding Pseudo-Profound Statements
}

\author{
IGOR RIŽNAR \\ University of Primorska, Slovenia \\ igor.riznar@fm-kp.si \\ JANA SUKLAN \\ Newcastle University, United Kingdom \\ jana.suklan@newcastle.ac.uk
}

After examining a rather small body of research on bullshit, we focus on the bullshit receptivity of Slovenian and Finnish teachers and students. Finnish higher education system and management schools were ranked substantially higher by the Global Economic Forum in 2015. Out of 144 countries, Slovenian higher education system is ranked 48th (scoring 4.1 on a scale from 1-7), Finnish second (5.9), with Finnish management schools taking tenth place (5.6) and Slovenian 74th. Being teachers ourselves, we thought it would be interesting to see if there are any substantial differences in recognizing bullshit statements between Slovenian and Finnish educators and students. We asked respondents to assess the level of profoundness in a set of 15 statements, of which only three were meaningful. Prior to this, the respondents were requested to complete the 18 -item Need for Cognition ( $\mathrm{NFC}$ ) scale and the 16-item Faith in Intuition (FI) scale to see if those with higher NFC/FI scores are better or worse at recognizing bullshit. With an average score of 1.54 on the NFc scale, our respondents were not very likely to engage in and enjoy effortful cognitive activities. On the other hand, with the score as low as 1.27 on the Fi scale, our respondents were also unlikely to trust their feelings and intuition. As for the pseudo-profound statements, they were rather keen on giving high scores (average 2.94) to sentences lacking any meaning. Our research proved that there is a negative correlation between the Need for Cognition and pseudo-profound statements for the whole sample. On the other hand, this is not statistically significant for the subsample of Finnish teachers and students, for the subsample of both Finnish and Slovenian students, where it is neither present nor statistically significant, and for the subsample of teachers (Slovenian and Finnish) where the correlation is negative, but not statistically significant. As for the Faith in Intuition and pseudo-profound statements, a positive correlation does not exist, except for the subsample of Slovenian and Finnish teachers. Finally, our research proved that the correlation between Need for Cognition and Faith in Intuition is strong, positive and statistically significant. Faced 
with the esoteric bullshit statements, participants might not want to endure the struggle to grasp the meaning of the statements and simply rated vacuous statements as profound either due to the lack of motivation to engage in cognitive activities or because they simply assumed, in a face-saving fashion, that the statements must have been somewhat meaningful. The results of our research revealed that our respondents considered many bullshit statements as substantially more profound than the three statements by Voltaire, Einstein and Robinson.

Key words: bullshit, pseudo-profound statements, need for cognition, faith in intuition

https://doi.org/10.26493/1854-4231.14.34-57

\section{Introduction}

In some way, the title of this article is plain bullshit, because we have to admit at the very beginning that we are unlikely to provide a definitive answer to the above question. In addition, ubiquitous as bullshit seems in our everyday life it is, we believe, not the most important part of our time. Bullshit, in our opinion, is interesting, because it is an extremely challenging topic analytically. We are not sure if there is more bullshit today than, say, twenty or hundred years ago, but we believe that the problem should nevertheless be tackled with all seriousness and scientific rigor, the more so because many of the researchers, ourselves included, mentioned below believe that bullshit, in all its varieties, is here to stay. Thus, we need a coherent, consistent, comprehensive and yet concise understanding of the essence of bullshit. The existing theories of bullshit surveyed below shed some valuable light on the problem at hand.

This article draws upon a number of writings, both essayistic and scientific and occasionally pseudo-scientific (Tietge 2006; Dalton 2016) that deal with bullshit in different ways. Frankfurt's essay, which was first published in 1986 in Raritan Review, and later reappeared as a book published by Princeton University Press in 2005 is our starting point. Our second source is the article by Pennycook et al. (2015), which focused on pseudo-profound bullshit, i.e. statements with correct grammatical structure but no meaning. Their research results suggest that 'a bias toward accepting statements as true may be an important component of pseudo-profound bullshit receptivity' (Pennycook et al. 2015, 549). Their focus is different from what is found in the philosophy of bullshit (Black 2015; Buekens and Boudry 2015; Frankfurt 2005), because they are primarily interested in the factors 'that predispose one to become or to resist becoming 
a bullshitee and not in goals and intentions' (Pennycook et al. 2015, 550) of bullshitters. They give two reasons why some people rate pseudo-profound bullshit as profound: first, some people may have a stronger bias toward accepting things as true or meaningful and second, some people are simply unable to detect bullshit. Taking into account that there are many different types of bullshit, different analytic cognitive processes, ranging from skepticism to logical reasoning, should be engaged for their detection. The investigation of Pennycook et al. focuses only on 'pseudo-profound bullshit that is missing any obvious external cue that skepticism is required' (2015, 551) in order to find out if there are 'consistent and meaningful individual differences in the ability to spontaneously discern or detect pseudo-profound bullshit' (p. 551).

Clever dishonesty found in political discourse, pomposity and vacuous jargon in academic discourse, lack of knowledge in academic essays, regurgitating encouraged by teachers are too often tolerated and sometimes even encouraged. Smagorinsky et al. (2010) come to the conclusion in their study of bullshit in academic writing that 'bullshit is indeed good stuff, perhaps even teachable' (Smagorinsky et al. 2010, 402) and 'that the generative potential of bullshitting as we have operationalized it for this study may benefit student writers as they learn to write within disciplinary expectations' (Smagorinsky et al. 2010, 402). These are the very 'disciplinary expectations' that may potentially lead to 'serious rhetorical sickness' in Billig's (2013) parlance and which should certainly not force potentially critical voices into the retreat of quietism and passivity. This is one of the main reasons why we believe that the concept under discussion should be thoroughly and systematically investigated. We should not allow bullshitters of different calibers to pollute our mental landscape day in day out, because of the fear that we may become pseudo-profound ourselves. It is a good thing to distinguish between useful talk, white lies, harmless bullshitting (bull session as described by Frankfurt) and mindfucking. We will not deliberate on the concept of mindfucking, which was investigated by McGinn (2008). On the other hand, and in a nod to McGinn, the ubiquity of bullshitting may lead to mindfucked individuals, therefore the concept of bullshitting and mindfucking should be studied and analysed together.

In our first draft of this paper we were toying with the idea that a suitable title for it could be 'From Oprah to Chopra.' Deepak Chopra gained an interview on Oprah Winfrey Show in 1993 and sold 400,00o copies of his infamous book (Chopra 1993), which partly 
explains how bullshit reproduces. As stated in the conclusion of the Pennycook et al article, bullshit sells, Chopra has more than 2.5 million followers on Twitter and has written more than twenty New York Times bestsellers. It is therefore high time we started teaching our students 'real-life' critical thinking skills necessary to identify what is profound and what is lacking any concern for meaning. Chopra, unfortunately, is just one example, as lack of meaningfulness is also present in political discourse, marketing language and academia (Sokal 2008). The atomization of academic practice and the high walls built by publishers of academic journals that protect pseudo-intellectuals from being read and properly assessed is most certainly one of the reasons for the ubiquity of bullshit in academia. We agree with Larivière, Haustein, and Mongeon $(2015,13)$ that it is up to the scientific community to change the system in a similar fashion and in parallel to the open access and open science movements' and add that this will not only save a large proportion of our universities money but also help reduce the amount of published bullshit.

In his Introduction to Language, Cognition, and Human Nature, Steven Pinker (2013) stresses the importance of clarity and intellectual rigor in both popular and academic writing. Helen Sword, in her Stylish Academic Writing (2012) showed that, after studying the literary style of five hundred academic articles, only a few academic articles were well written. In the same vein, Billig (2013) starts his book by saying: 'This is a book which complains about poor writing in the social sciences' $(2013,1)$. His witty and highly entertaining book analyses two things: the conditions under which academics in social sciences are working (massive expansion of higher education institutions, the number of students and teachers, self-promotion, competition between disciplines, which are divided into smaller and smaller circles) and the linguistic nature of their work (technical terminology becomes superior to ordinary language, noun-based style of writing i.e. reification and nominalization, passivization, etc.). Ever-narrower academic specialization together with the growth of higher education (with the increase of both the number of students and teachers) have led to turning actions into lofty abstractions, which, in turn, have made academic prose incomprehensible and difficult to grasp. The multi-syllabled pomposity and obscurity found in academic writing is, alas, the result of much hard labour to learn the practice, because the empty jargon has to be learned in order to write and publish articles even if you have little or nothing to say. In Billig's words: 'Just like the learning of a foreign language, 
so the acquiring of academic language occurs gradually over time.' $(2013,58)$

Let us consider the following statements:

1. Colorless green ideas sleep furiously.

2. Tea knows precisely why it is tea.

3. Today, science tells us that the essence of nature is sharing.

4. Anything that is too stupid to be spoken is sung.

5. Speaking German makes me reason more carefully.

6. Different cultures and languages build words into structures of meanings that derive from specific social, historical and cultural circumstances. In translation, we therefore have to deal with the comparability of these structures of meaning in different languages.

Sentence (1) has correct grammatical structure, yet the probability that these words have previously occurred in this order is close to zero, thus we would, without employing too much mental effort, immediately recognize it as nonsense. The sentence was composed by Noam Chomsky (2002) in order to demonstrate the distinction between syntax and semantics of a language.

Sentence (2) is also easily recognized as meaningless. Taken from its context (a funny, playful, absurdist line published in Tomaž Šalamun's book of poetry Poker published in 1966) it may appear as meaningless.

Sentence (3) is bullshit par excellence. It is a combination of big words (science, essence, nature, sharing) used to impress, but with no clear meaning.

Sentence (4) is, in our opinion, if not definitely, at least fairly profound. Everyone who listens to lyrics of contemporary pop singers can easily find both meaning and truth in it.

Sentence (5) is known by the name stereotype and can also be considered a bullshit statement.

Two sentences in (6) by Čebron (2002) represent pseudo-scientific discourse, which, after being translated into plain English language, leave the reader with truism and little more. We presume that the two sentences were written with the purpose to make a contribution towards the understanding of the importance of culture in translation studies, yet thorough linguistic analysis shows that such language is both incoherent and empirically false.

For the purpose of our study, we included only 12 statements of type (c) and three statements of type (d). We wanted to find out how 
successful our respondents were in recognizing bullshit and distinguishing bullshit from non-bullshit. In addition, we asked participants to complete the 18-item Need for Cognition scale (NFC) and the 16-item Faith in Intuition scale (FI) to see if those with higher NFC scores are better at recognizing bullshit and if respondents with higher FI scores are worse at detecting bullshit.

\section{On Bullshit}

We live in the world in which, it seems at least occasionally, bullshit is ubiquitous. 'One of the most salient features of our culture,' writes Harry G. Frankfurt (2005), 'is that there is so much bullshit.' We are all aware of it and we all contribute our share to it. But because we take the situation for granted, very little work has been done on the subject. According to Frankfurt speech emptied of all informative content 'is unavoidable whenever circumstances require someone to talk without knowing what he is talking about' (Frankfurt 2005, 63). For Frankfurt the essence of bullshit is the 'lack of connection to a concern with truth - this indifference to how things really are' (pp. 33-4). Liars, in Frankfurt's opinion, are not so dangerous as bullshitters, because someone who ceases to believe in the possibility of identifying certain statements as true and others as false (p. 61) is greater enemy of the truth than the liar. Frankfurt ridicules those who undermine 'confidence in the value of disinterested efforts to determine what is true and what is false, and even in the intelligibility of the notion of objective inquiry' (p. 65).

In Politics and the English Language (2013) wrote about nonsensical and meaningless language that comes from incapacity, indifference or sheer laziness. Such banal linguistic discourse has dire consequences, because it spreads among people with such an ease, and too often goes unnoticed.

Cohen (2002) pointed to bullshit in academic writing. Academese is full of 'unclarifiable unclarity' or nonsense that is often considered as brilliance rather than sheer banality. Spreading of such bullshit is guaranteed by followers and students, who defend the idea as profound rather than accepting its vagueness. Cohen proposes two ways of detecting this kind of bullshit: translation and negation. Through an attempt to translate or paraphrase a statement one will 'create something that isn't recognizable as a version of what was said' (Cohen 2002, 130). The statement is bullshit if you can assert the negation of the statement without loss of plausibility. Cohen himself presented the difference between his concept of bullshit and Frankfurt's concept in the following way: 
TABLE 1 The Difference between Cohen's and Frankfurt's Concept of Bullshit

\begin{tabular}{lllll}
\hline Concept & $\begin{array}{l}\text { Context of } \\
\text { Utterance }\end{array}$ & $\begin{array}{l}\text { Corresp. ofd } \\
\text { Definitions }\end{array}$ & Primary Locus & Essence \\
\hline $\begin{array}{l}\text { Frankfurt's } \\
\text { Bullshit }\end{array}$ & Everyday life & 2 & Activity & $\begin{array}{l}\text { Indifference to } \\
\text { truth }\end{array}$ \\
\hline $\begin{array}{l}\text { Cohen's } \\
\text { Bullshit }\end{array}$ & The academy & 1 & Output & Unclarifiability \\
\hline
\end{tabular}

Notes Adapted from Cohen $(2002,338)$.

By examining bullshit in an empirical fashion, Pennycook et al. (2015, 559-61) propose two mechanisms that explain why individuals rate bullshit as profound: first, some people may simply be more prone to relatively high profundity ratings or may have an uncritically open mind, the so-called intuitive reflexive open mindednesss, which differs from the reflective open-mindedness 'that searches for information as a mean to facilitate critical analysis and reflection' (Pennycook et al. 2015, 560) and, second, some people may confuse vagueness for profoundity because of their inability to detect bullshit. Pennycook et al. found that susceptibility to pseudo-profound bullshit strongly positively correlated with religious beliefs, beliefs in the paranormal, conspiracy theories and complementary and alternative medicines. On the other hand, it was negatively correlated with measures of intelligence, skepticism and rationality, but not numeracy.

Bullshit receptivity and cognitive reflection were a subject of empirical study in Bullshit Detection and Cognitive Reflection (Pennycook 2016), where the efficiency of bullshit detection was predicted by the propensity to engage reflective reasoning. In the study, respondents were asked to decide whether the sentences were nonsense or meaningful and the results revealed that pseudo-profound bullshit can be reliably detected when participants are told explicitly to do so, yet they were much worse at detecting bullshit than they were at recognizing motivational sentences.

Neil Postman (1969) discussed the taxonomy of bullshit in his speech delivered at the National Convention for the Teachers of English in November 1969. Postman believes that the best thing schools can do for our children is to equip them with 'crap-detectors' in order to be able to distinguish between useful talk and bullshit. Postman believes that 'people are exposed to more bullshit than it is healthy for them to endure' $(1969,1)$ and gives the following varieties of bullshit:

1. Pomposity - big-time words used as a triumph of style over sub- 
stance: fancy titles, words, phrases, and sentences to obscure their own insufficiencies.

2. Fanaticism - deadly and ignorant statements (e.g. 'Niggers are lazy'); Eichmannism is the form of bullshit which accepts as its starting and ending point official definitions, rules, and categories without regard of the realities of particular situations, e.g. 'If we do it for one, we have to do it for all.'

3. Inanity - 'sentences of people who are in no position to render informed judgments on what they are talking about and yet render them with élan and, above all, sincerity.'

4. Superstition - ignorance presented in the cloak of authority.

5. Earthiness - based on the assumption that if we use direct, offcolour, four letter words like crap or shit, we somehow are making more sense than if we observed the proper language customs.

What do people need in order to be able to recognize bullshit? Postman believes that one needs, first and foremost, 'a keen sense of the ridiculous' $(1969,5)$ and goes on by saying that 'sensitivity to the phony uses of language requires knowledge of how to ask questions, how to validate answers, and certainly, how to assess meanings' (p. 6). Postman's beautifully rounded essay closes with a sound premise that there is no more precious environment than our language environment (pp. 6-7).

De Wall (2006) believes that people produce bullshit because of the lack of an attitude of genuine inquiry. Bernal (2006), on the other hand, thinks that the ubiquity of bullshit is the result of personality disorders or neuroses that lead to a biased perception of reality and thus a biased and inaccurate use of language. For Bernal some people 'have bullshit deeply embedded in their personalities' (2006, 70).

Maes and Schaubroek (2006) believe that bullshit is not always a bad thing, "because in many circumstances the concern for truth and accuracy is not - and should not be - our primary concern' ( $p$. 177). Even more importantly, they also, albeit briefly, write about the plethora of pseudo-scientific bullshit, a topic neglected by both Frankfurt and Cohen. This extremely important kind of bullshit deserves to be thoroughly studied, because it is equally damaging as bullshit produced by academics or company mission writers.

For Richardson (2006) bullshit is so widespread that one cannot engage in some activities without engaging in bullshit. He sees bullshit in grant proposals, letters of reference and company mission 
statements. In order to overcome bullshit we have to 'fundamentally rethink our values' (Richardson 2006, 97) or we will get what we deserve: bullshit.

Belfiore (2009) explores bullshit in the contemporary British public sphere and academia. The corruption of the language of public discourse is not a new phenomenon. Orwell (2013) reprimanded political language in 1946 in his Politics and English Language. In her conclusion, Belfiore stresses the importance of 'intellectual humility' (2009, 355) which refers to 'he acceptance that when exploring complex questions (and cultural and political questions are inescapably complex), the researcher needs to accept that it might not be possible to find easy answers that can tidily fir into a journal article (p. 355) and expresses a belief that it is a duty of researchers to commit to the principle of 'rigour and precision' (p. 354) instead of pursuing knowledge for knowledge's sake.

A number of important issues are raised by Nielsen (2015). He summarizes his findings by saying that 'social media seem to be accompanied by a lot of bullshit because we know so little and because there is a lot at stake' (Nielsen 2015, 2). Further on, he says that we should improve our 'theoretical, methodological, and substantial understanding and accumulate new insight about a wide variety of important cases and contexts' (2). Unintended bullshit is, according to Nielsen, often kept alive through regurgitation. He proposes to check if a statement is bullshit by asking a simple question 'how do you know?'

In Bluff and Bull in Education, Sassoon (2005) gives examples of disregard for truth in educational context, including media, educational professionals and politicians. Under the pretense of sincerity, a lot of bullshit is keenly accepted by all participants in education.

Contrary to Eubanks and Schaeffer (2008) believe that bullshit is at least potentially a lie (e.g. a sales pitch or a corporate banality like 'Your call is important to us.'). They also write about academic bullshit among professors, both from the point of view of non-academics, who call such writing bullshit when 'they mean that it uses jargon, words whose meanings are so abstract and vague as to seem unrelated to anyone's experience' (p. 381) and from the academic's point of view who "believe their own bullshit. They hide behind language that may be as slight, or exaggerated, or obfuscatory as any sales pitch or fish story' (p. 382). Eubanks and Schaeffer argue that academic bullshit is a product of the conventions required by academic writing, where authors must maintain a certain tone and voice. In other words, authors suggest that some varieties of academic bull-

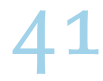


shit may be both unavoidable and beneficial, a defense of a certain type of academic language that is difficult to accept.

Mittelstaedt (2007) believes that Frankfurt's book should be of particular interest to marketers, because the majority of promises made to the consumers through different media are pure bullshit. Mittelstaedt points to an interesting problem that deserves further exploration, namely 'why do people put up with so much bullshit from marketers?' (p. 198) and raises a number of additional questions: 'Why don't people show more impatience or irritation? Are they na?ve and believe they are learning something of importance? Or do they appreciate the skill of a true Bs artist in much the same way they appreciate the skill of, say, an excellent tennis player?' (p. 189).

Selwyn (2016) analyses educational use of terms related to digital technology, which tend to be discussed in enthusiastic and often exaggerated language, which requires far more critical scrutiny than it currently receives. According to Selwyn $(2016,3)$ the language used to describe what is going on in education and technology could be said to conform to Frankfurt's description of language that is excessive, phony and generally repeated 'quite mindlessly and without any regard for how things really are' (Frankfurt 2005, 30). Ignorance of facts and contextual realities is the main characteristics of the language used in education and technology, the world of advertising, real estate, education in general and education leadership, learning styles, political speech, academic discourse, legal profession and contemporary art. Selwyn (2016) draws parallels with Giroux (2013) who writes about 'public stupidity' that is preserved through our lazy preference for jocular, superficial and empty talk not only in popular but also in professional and academic discourse. Selwyn (2016, 6) sums up by saying that thoughtful language is clearly a key element to fight bullshit when speaking or writing about education and technology.

Quandt (2007), inspired by philosophical insight, like many others, ourselves included, of Harry G. Frankfurt (2005), believes that wine trade is intrinsically bullshit-prone, thus attracting many 'bullshit artists' (p. 135), who are able to describe a wine using 20 attributes. 'The pretense that we shall be able to discern all those tastes and aromas is pure bullshit' (p. 134) is the main message of Quandt's contribution towards bullshit analysis.

Dalton (2016) raised a methodological concern regarding the Pennycook et al. $(2015,121)$ study, by claiming that computer generated meaningless statements may be 'subjectively profound' and may only seem nonsensical due to our 'Western analytical perspec- 
tive.' As a matter of fact, Dalton is open-minded to the extend that he is willing to assign profoundness to bullshit statements when an individual is able to construct meaning for bullshit items. We believe that such tolerance for bullshit is unacceptable and utterly damaging, because bullshit statements represent language which conceals or prevents thought rather than inspires insight or, in Dalton's doublespeak provides 'glimpses of insight and wisdom' Pennycook et al. $(2015,121)$. The irrelevance of Dalton's claims was addressed in Pennycook et al. (2016) who stated that bullshit is defined in terms of how it is produced and not how it is interpreted.

In a recent study by Pfattheicher and Schindler (2016), profoundness in bullshit statements was more often perceived by politically conservative individuals. In other words, political conservatism was positively related to seeing profoundness in pseudo-profound statements.

\section{Study}

NEED FOR COGNITION

The Need for Cognition Scale is an assessment instrument that quantitatively measures the extent to which individuals are inclined towards effortful cognitive activities. It measures 'the tendency for an individual to engage in and enjoy thinking' (Cacioppo and Petty $1982,116)$. The original scale included 34 questions, but we used the shortened scale (18-item format). We asked the individuals to rate the extent to which they agree with each of 18 statements, following Cacioppo, Petty, and Kao (1984). Sample statements include 'Thinking is not my idea of fun,' 'I only think as hard as I have to,' and 'I would prefer complex to simple problems.' Participants were asked to describe the extent to which they agree with each statement using a 5-point scale with the following values: definitely uncharacteristic of you (1), somewhat uncharacteristic of you (2), uncertain (0), somewhat characteristic of you (3) and extremely characteristic of you. (4) Out of the 18 statements, 9 were reverse scored, which means that if an individual very strongly agrees with 'I find satisfaction in deliberating hard and for long hours,' the individual is given 4 points (the item is scored positively). If the individual very strongly disagrees with 'Learning new ways to think doesn't excite me very much,' the individual is given 4 points since the item is scored negatively (i.e. reverse scored). The highest possible score was 72 .

The Need for Cognition has been found to be positive correlated with academic curiosity (Olson, Camp, and Fuller 1984), academic

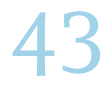


performance (Wang and Newlin 2000), demanding cognitive activities like learning a language (Oxford 1990) and a preference for new experiences in general (Venkatraman et al. 1990; Venkatraman and Price 1990).

\section{FAITH IN INTUITION}

We used a 16-item questionnaire known as Faith in Intuition scale to measure reliance on intuitive decision making. Faith in Intuition is a self-report scale which reflects engagement and trust in one's own intuition. According to Epstein et al. (1996) and Keller, Bohner, and Erb (2000), Faith in Intuition is independent of the engagement in cognitive activity as measured by the Need of Cognition Scale.

Out of 16 statements (e.g. I trust my initial feelings about people.), seven were reverse scored (e.g. I suspect my hunches are inaccurate as often as they are accurate.), with the highest possible score amounting to 64 . The participants were asked to indicate to what extent each statement is characteristic of them by using the following scale: 1 = definitely uncharacteristic of you (definitely not true of myself), 2 = somewhat uncharacteristic of you; $0=$ uncertain, $4=$ somewhat characteristic of you and $5=$ extremely characteristic of you (definitely true of myself).

BULLSHIT STATEMENTS

Examples of bullshit statements were generated by three websites: 'The New Age Bullshit Generator' (http://sebpearce.com/bullshit/) (e.g. Today, science tells us that the essence of nature is sharing.), which compiles profound sounding statements by randomly combining buzzwords into sentences with perfect syntactic structure that are designed to impress but are meaningless, 'Wisdom of Chopra' (http://www.wisdomofchopra.com) (e.g. Freedom is the continuity of an expression of actions.), which generates sentences from a set of profound sounding words that can be found in Deepak Chopra's Twitter stream put together at random. The last three statements were generated using Artbollocks (http://www.artybollocks.com) generator (e.g. With influences as diverse as Caravaggio and Francis Bacon, new combinations are manufactured from both mundane and transcendent dialogues).

Three of the 15 statements $(5,8$ and 10) were not bullshit statements, but genuinely meaningful statements leaning towards a certain degree of profoundness (Responding to works of art is also a creative process (Sir Ken Robinson). The significant problems we face today cannot be solved at the same level of thinking we were at 
when we created them (Albert Einstein). Anything that is too stupid to be spoken is sung (Voltaire)).

The participants were asked to read the instructions carefully before they decide which of the statements below belong to the socalled pseudo-profound bullshit (statements that are designed to impress but are absent of any actual concern for truth and meaning, in other words, meaningless sentences) and which are profound (statements having or showing great knowledge and insight).

They were asked to rate every statement on a scale between definitely pseudo-profound - somewhat profound - fairly profound very profound - definitely profound by circling the appropriate item.

\section{Sample and Methods}

PARTICIPANTS

A total of 221 participants $(61,1 \%$ female, $72,4 \%$ from Slovenia) were included in the survey. We received 61 responses $(77,0 \%$ from students) From Finland and 160 responses (80,6\% from students) from Slovenia.

Only students and teachers with excellent command of English language were selected (c1 or c2 on the Common European Framework of Reference for Languages scale) for our study. Slovenian students were recruited from the University of Primorska, Faculty of Management, whereas teachers of three largest Slovenian universities were asked to participate in the study (University of Ljubljana, Faculty of Economics, University of Maribor, Faculty of Economics and Business and University of Primorska, Faculty of Management). Finnish students and teachers were recruited form the Mikkeli University of Applied Sciences, Finland.

In order to provide adequate power and stability of the correlations, we wanted to reach at least 300 participants, but were forced to exclude almost one third of respondents due to a number of skipped statements.

\section{METHODS}

The questionnaire used in our study was divided into four parts: demographic questions were followed by the Need for Cognition scale, the Faith in Intuition scale and, finally, pseudo-profound statements. Both the Need for Cognition scale and the Faith in Intuition scale were used because they both had excellent reliability ( 0.93 (NFC) and 0.94 (FI)) in Pennycook et al. $(2015,554)$ research.

The reliability of the construct is above $0,7(\alpha=0.78)$, thus within 
the acceptable values of alpha (Tavakol and Dennick 2011). The reliability of the specific construct then ranges from rationality test - the Need for Cognition $(\alpha=0.78)$, intuition test - the Faith in Intuition $(\alpha=0.77)$ to statements about bullshit $(\alpha=0.69)$. We computed the rationality test, intuition test and bullshit statements as the average of the given number of single statements. In original questionnaire, all statements were on the Likert scale, which was then recoded and weighted on the basis of the meaning of the statement. The respondents that chose the central score were given o points, the maximum value was from o to 4 .

In our study, we asked participants to rate 12 pseudo-profound bullshit statements and three meaningful statements on a scale ranging between definitely pseudo-profound (1) - somewhat profound (2) - fairly profound (3) - very profound (4) - definitely profound (5) with the goal to find out how receptive respondents are to bullshit. We argue that high ratings indicate high receptivity toward bullshit.

Within the statements on bullshit only three statements were recoded. Rules (available upon request) were defined in order to recode the statements on scale from o to 4 . Each battery of statements was tested for unidimensionality and only statements that took part within this dimension were selected to compute a proxy. Finally, we computed three proxys: NC, FI and bullshit statements. The proxys were computed as a regression method within factor analysis and were all normally distributed. In such manner we also tested for adequate construct validity. In order to test correlation between them we employed Pearson correlation coefficients. To test the difference in mean values of the observed variables between four groups of participant we computed analysis of variance (ANOVA) or alternative Kruskal-Wallis test. The level of significance was set at $5 \%$.

\section{Results and Discussion}

In general, the statements within the segment Need for Cognition were given the average mark of 1.5 . The highest rated statements were:

- Learning new ways to think doesn't excite me very much ( $\mathrm{M}=$ 2.6).

- Thinking is not my idea of fun $(\mathrm{M}=2.6)$.

- I try to anticipate and avoid situations where there is a likely chance I will have to think in depth about something $(\mathrm{M}=2.5)$. 
TABLE 2 Mean Values of Statements: 'Need for Cognition' within Four Groups of Participants

\begin{tabular}{|c|c|c|c|c|}
\hline Statement & (1) & $(2)$ & (3) & (4) \\
\hline I would prefer complex to simple problems. & 2.6 & 1.8 & 2.5 & 1.6 \\
\hline $\begin{array}{l}\text { I like to have the responsibility of handling a situation that } \\
\text { requires a lot of thinking. }\end{array}$ & 3.1 & 2.3 & 2.8 & 2.1 \\
\hline Thinking is not my idea of fun. & $3 \cdot 3$ & 2.7 & 3.3 & 2.4 \\
\hline $\begin{array}{l}\text { I would rather do something that requires little thought } \\
\text { than something that is sure to challenge my thinking abil- } \\
\text { ities. }\end{array}$ & 3.1 & 2.5 & 2.6 & 2.1 \\
\hline $\begin{array}{l}\text { I try to anticipate and avoid situations where there is a } \\
\text { likely chance I will have to think in depth about something. }\end{array}$ & 3.4 & 3.0 & 3.2 & 2.1 \\
\hline I find satisfaction in deliberating hard and for long hours. & 2.1 & 1.6 & 2.7 & 1.5 \\
\hline I only think as hard as I have to. & 2.6 & 2.2 & 2.2 & 2.1 \\
\hline $\begin{array}{l}\text { I prefer to think about small, daily projects than long-term } \\
\text { ones. }\end{array}$ & 2.6 & 2.5 & 2.6 & 2.0 \\
\hline $\begin{array}{l}\text { I like tasks that require little thought once I've learned } \\
\text { them. }\end{array}$ & 3.6 & 2.2 & 3.1 & 1.9 \\
\hline $\begin{array}{l}\text { The idea of relying on thought to make my way to the top } \\
\text { appeals to me. }\end{array}$ & 3.1 & 1.9 & 2.7 & 2.1 \\
\hline $\begin{array}{l}\text { I really enjoy a task that involves coming up with new so- } \\
\text { lutions to problems. }\end{array}$ & 3.0 & 2.7 & 2.9 & 2.3 \\
\hline Learning new ways to think doesn't excite me very much. & 3.4 & 3.2 & $3 \cdot 3$ & 3.0 \\
\hline I prefer my life to be filled with puzzles that I must solve. & 2.9 & 3.0 & 2.9 & 2.8 \\
\hline The notion of thinking abstractly is appealing to me. & 3.0 & 2.9 & $3 \cdot 3$ & 2.8 \\
\hline $\begin{array}{l}\text { I would prefer a task that is intellectual, difficult, and im- } \\
\text { portant to one that is somewhat important but does not } \\
\text { require much thought. }\end{array}$ & 3.0 & 2.9 & 3.0 & 2.8 \\
\hline $\begin{array}{l}\text { I feel relief rather than satisfaction after completing a task } \\
\text { that required a lot of mental effort. }\end{array}$ & 2.9 & 2.6 & 2.9 & 2.7 \\
\hline $\begin{array}{l}\text { It's enough for me that something gets the job done; I } \\
\text { don't care how or why it works. }\end{array}$ & 3.8 & 3.1 & 3.4 & 2.9 \\
\hline $\begin{array}{l}\text { I usually end up deliberating about issues even when they } \\
\text { do not affect me personally. }\end{array}$ & 2.7 & 3.0 & 2.8 & 2.8 \\
\hline
\end{tabular}

Notes Column headings are as follows: (1) a teacher in Finland, (2) a student in Finland, (3) a teacher in Slovenia, (4) a student in Slovenia.

- It's enough for me that something gets the job done; I don't care how or why it works $(\mathrm{M}=2.5)$.

Statements within the segment Faith and Intuition were given the average mark of 1.3. The highest rated statements were:

- I don't have a very good sense of intuition ( $\mathrm{M}=2.4)$.

- I generally don't depend on my feelings to help me make decisions $(\mathrm{M}=2.1)$. 
TABLE 3 Mean Values of Statements: 'Faith and Intuition' within Four Groups of Participants

\begin{tabular}{|c|c|c|c|c|}
\hline Statement & (1) & (2) & (3) & (4) \\
\hline I don't have a very good sense of intuition. & 2.4 & 2.5 & 2.6 & 2.3 \\
\hline $\begin{array}{l}\text { Using my gut-feelings usually works well for me in work- } \\
\text { ing out problems of my life. }\end{array}$ & 2.6 & 2.8 & 2.3 & 2.2 \\
\hline $\begin{array}{l}\text { I can usually feel when a person is right or wrong, even if } \\
\text { I can't explain how I know. }\end{array}$ & 2.9 & 2.6 & 2.1 & 2.4 \\
\hline $\begin{array}{l}\text { My snap judgments are probably not as good as most peo- } \\
\text { ple's. }\end{array}$ & 1.6 & 1.9 & 1.5 & 1.6 \\
\hline I trust my initial feelings about people. & 2.7 & 2.6 & 2.5 & 2.7 \\
\hline $\begin{array}{l}\text { I suspect my hunches are inaccurate as often as they are } \\
\text { accurate. }\end{array}$ & 3.1 & $3 \cdot 3$ & 3.0 & 3.1 \\
\hline I believe in trusting my hunches. & 2.4 & 2.2 & 2.0 & 2.3 \\
\hline I like to rely on my intuitive impressions. & 2.7 & 2.8 & 2.0 & 2.2 \\
\hline Intuition can be a very useful way to solve problems. & 2.0 & 2.8 & 2.2 & 2.3 \\
\hline $\begin{array}{l}\text { I often go by my instincts when deciding on a course of } \\
\text { actions. }\end{array}$ & 1.4 & 2.5 & 1.9 & 2.3 \\
\hline I don't like situations in which I have to rely on intuition. & 2.6 & 2.0 & 2.1 & 2.0 \\
\hline $\begin{array}{l}\text { I think there are times when one should rely on one's in- } \\
\text { tuition. }\end{array}$ & $3 \cdot 3$ & 2.6 & 2.4 & 2.1 \\
\hline $\begin{array}{l}\text { I think it is foolish to make important decisions based on } \\
\text { feelings. }\end{array}$ & 1.7 & 2.1 & 2.0 & 1.8 \\
\hline $\begin{array}{l}\text { I don't think it is a good idea to rely on one's intuition for } \\
\text { important decisions. }\end{array}$ & 2.1 & 1.7 & 1.6 & 1.6 \\
\hline $\begin{array}{l}\text { I generally don't depend on my feelings to help me make } \\
\text { decisions. }\end{array}$ & 2.3 & 2.1 & 2.0 & 2.0 \\
\hline I tend to use my heart as a guide for my actions. & 1.6 & 2.6 & 0.9 & 2.1 \\
\hline
\end{tabular}

Notes Column headings are as follows: (1) a teacher in Finland, (2) a student in Finland, (3) a teacher in Slovenia, (4) a student in Slovenia.

- I don't like situations in which I have to rely on intuition ( $\mathrm{M}=$ 2.0).

Statements on bullshit, on the other hand, were given the average mark of 3.0. The highest rated statements were:

- Freedom is the continuity of an expression of actions $(\mathrm{M}=3.4)$.

- Anything that is too stupid to be spoken is sung $(\mathrm{M}=3.4$; not a bullshit statement).

- The human nervous system corresponds to intrinsic experiences $(\mathrm{M}=3.2)$.

- Imagination is the wisdom of an expression of sensations $(\mathrm{M}=$ 3.2). 
TABLE 4 Mean Values of Statements: 'On Bullshit' within Four Groups of Participants

\begin{tabular}{|c|c|c|c|c|}
\hline Statement & (1) & $(2)$ & (3) & (4) \\
\hline Evolution is a modality of innumerable space-time events. & 2.3 & 3.3 & 2.8 & 3.0 \\
\hline Intuition results from an abundance of fulfillment. & 1.8 & 2.8 & 1.9 & 2.8 \\
\hline Experiential truth nurtures incredible opportunities. & 2.8 & 3.4 & 2.5 & 3.2 \\
\hline $\begin{array}{l}\text { The web of life is inextricably connected to the doorway to } \\
\text { experiences. }\end{array}$ & 2.5 & 3.2 & 2.3 & 3.0 \\
\hline Responding to works of art is also a creative process. & 2.8 & 2.6 & 2.6 & 2.4 \\
\hline Hidden meaning relies on species specific happiness. & 1.8 & 2.8 & 1.7 & 2.9 \\
\hline Freedom is the continuity of an expression of actions. & 2.0 & 3.6 & 2.8 & 3.5 \\
\hline $\begin{array}{l}\text { The significant problems we face cannot be solved at the } \\
\text { same level of thinking we were at when we created them. }\end{array}$ & $3 \cdot 3$ & 2.8 & 2.1 & 2.7 \\
\hline Good health reflects total acceptance of opportunities. & 3.3 & 3.0 & 1.8 & 3.2 \\
\hline Anything that is too stupid to be spoken is sung. & 3.8 & 3.6 & 4.1 & 3.1 \\
\hline Imagination is the wisdom of an expression of sensations. & 2.5 & 3.6 & 2.6 & 3.1 \\
\hline $\begin{array}{l}\text { The human nervous system corresponds to intrinsic expe- } \\
\text { riences. }\end{array}$ & $3 \cdot 3$ & 3.4 & 3.3 & 3.2 \\
\hline $\begin{array}{l}\text { My work explores the relationship between new class } \\
\text { identities and midlife subcultures. }\end{array}$ & 1.8 & 2.8 & 1.8 & 2.9 \\
\hline $\begin{array}{l}\text { With influences as diverse as Caravaggio and Francis Ba- } \\
\text { con, new combinations are manufactured from both mun- } \\
\text { dane and transcendent dialogues. }\end{array}$ & 2.5 & 2.6 & 1.7 & 2.7 \\
\hline $\begin{array}{l}\text { Today, science tells us that the essence of nature is shar- } \\
\text { ing. }\end{array}$ & 3.5 & 2.8 & 2.6 & 3.1 \\
\hline
\end{tabular}

NOTES Column headings are as follows: (1) a teacher in Finland, (2) a student in Finland, (3) a teacher in Slovenia, (4) a student in Slovenia.

In order to provide correlations, we analyzed the whole sample together and provide the results for two splittings: Slovenia, Finland and student, teacher and without further splitting within categories.

Firstly, we postulated that there is a negative correlation between the Need for Cognition and pseudo-profound statements. According to the general results this could be accepted, since the correlation between the Need for Cognition and pseudo-profound statements is negative, semi-string and statistically significant $(r=-0,183$, $p=0,023)$. Furthermore, according to the research results we could also accept this for the subsample of Slovenian teachers and students, since the correlation between the Need for Cognition and pseudo-profound statements is negative, semi-string and statistically significant $(r=-0.199, p=0.028)$. However, the results show that we could not accept this for the subsample of Finnish teachers and students, since the correlation between the Need for Cognition 
and pseudo-profound statements is not statistically significant $(r=$ $-0.181, p=0.179)$. In line with the research results, we need to reject our supposition for the subsample of students (Slovenian and Finnish), since the correlation between the Need for Cognition and pseudo-profound statements is not present or statistically significant $(r=-0.082, p=0.207)$. In addition, the results showed the correlation between the Need for Cognition and pseudo-profound statements is negative, but not statistically significant $(r=-0.241, p=0.160)$ for the subsample of teachers (Slovenian and Finnish).

Secondly, we postulated that there is a positive correlation between Faith in Intuition and pseudo-profound statements. According to the general results this could not be accepted, since the correlation between the Faith in Intuition and pseudo-profound statements does not exist $(r=0.092, p=0.153)$. In line with the results we have to reject this supposition for the subsample of Slovenian teachers and students, since the correlation between the Faith in Intuition and pseudo-profound statements does not exist $(r=0.096, p=0.175)$. The results showed we could reject the second postulation for the subsample of Finnish teachers and students, since the correlation between the Faith in Intuition and pseudo-profound statements does not exist $(r=0.061, p=0.374)$. The same holds true for the subsample of students, since the correlation between the Faith in Intuition and pseudo-profound statements does not exist $(r=0.033, p=0.368)$. In line with the results we could confirm our claim for the subsample of teachers (Slovenian and Finnish), since the correlation between the Faith in Intuition and pseudo-profound statements is positive, semi-string and statistically significant $(r=0.393, p=0.043)$.

Thirdly, we postulated that there is a negative correlation between Need for Cognition and Faith in Intuition. According to the results we could reject this, since the correlation between the Need for Cognition and the Faith in Intuition is strong, positive and statistically significant ( $r=0.401, p=0.000$ ), which counter intuitively tells us that the more respondents rely on rational decisions the more they use their intuitive senses. The research results showed that we could reject this for the subsample of Slovenian teachers and students, since the correlation between the Need for Cognition and the Faith in Intuition is strong, positive and statistically significant $(r=0.407, p$ $=0.000$ ). In line with the results we could reject this for the subsample of Finnish teachers and students, since the correlation between the Need for Cognition and the Faith in Intuition is strong, positive and statistically significant $(r=0.316, p=0.030)$. Based on the results our third assumption must be rejected for the subsample of students, 
since the correlation between the Need for Cognition and the Faith in Intuition is strong, positive and statistically significant $(r=0.477, p$ $=0.000$ ). Similarly, our assumption must be rejected for the subsample of teachers, since the correlation between the Need for Cognition and the Faith in Intuition is strong, positive and statistically significant $(r=0.393, p=0.043)$.

One of the differences between our article and that of Pennycook et al. (2015) lies in the selection of participants. In Pennycook et al. only participants who reported that English was their mother tongue were allowed to participate, whereas all our participants were nonnative speakers with a rather good command of English. We could have translated the questionnaire into Slovenian and Finnish, but deliberately decided not to do so. We wanted to test the study by Keysar, Hayakawa, and An (2012) who report that using a foreign language reduces decision-making biases (our willingness to take irrational risks in order to avoid suffering a loss). According to their findings using a foreign language activates what Kahneman (2011) calls System 2 (deliberative and slow, better at higher reasoning but effortful to activate and keep active) instead of System 1 (intuitive and quick, good for most purposes, but prone to cognitive traps) in order to tackle tricky questions. Our participants, who were faced with a slightly different problem, may indeed be less biased in their savings, investments and retirement decisions, but were rather unsuccessful at distinguishing profound statements from bullshit. Or they might be bilingual to the extent that the foreign language effect disappeared.

According to dual-process theory, two general types of processes operate in the mind (Evans and Stanovich 2013): Type 1 processes that generate so-called intuitive outputs autonomously and with little effort, and Type 2 processes that require a more effortful implementation of working memory capacity, often with the goal of overriding the Type 1 output. The results of our research revealed that, for our respondents, many bullshit statements were substantially more profound than the three statements by Einstein, Voltaire and Sir Ken Robinson.

\section{Future Research and Research Limitations}

As for the future endeavours in the field under discussion, we would recommend a shift towards real-life examples of bullshit statements taken, for example, from political, academic or marketing discourse. In addition, what a rather small body of present research on bullshit lacks is focus on the linguistic properties of pseudo-profound dis- 
course and linguistic capabilities of respondents. Bullshit is, above all, language 'that treats people in ways you do not approve of' (Postman 1969, 5).

Our research was based on bullshit statements generated from three webpages: The New Age Bullshit Generator, Wisdom of Chopra and Artbollocks generator. With the benefit of hindsight, it would have been better to prepare a collection of real-life and less hermetic bullshit statements for our respondents, combined with an equal number of meaningful statements.

In addition, relatively high profoundness scores for pseudo-profound statements are due to the scale (1. definitely pseudo-profound -2 . somewhat profound -3 . fairly profound -4 . very profound 5. definitely profound) used to assess the profoundness of chosen statements. To ask participants to mark bullshit statements according to their profoundness is somehow misleading, because the respondents are led to believe that the statements were selected for their profundity instead of the lack of it. We believe that the results would differ substantially if they were asked to rate statements according to the following scale: 1 . profound -2 . somewhat pseudoprofound -3 . fairly pseudo-profound -4 . very pseudo-profound -5 . definitively pseudo-profound.

A further limitation related to the set of chosen bullshit statements is the lack of context. Respondents trying to grasp the meaning of written discourse need context in order to uncover (the lack of) meaning in language. The absence of context was an additional factor responsible for relatively high average scores for bullshit items.

Last but not least, in self-report scales there is always the possibility that respondents are not entirely honest.

\section{Conclusion}

It is highly unlikely that pseudo-profound statements of all types in written and spoken discourse will cease to exist or decrease in quantity without attempts aimed at acquiring a better understanding of factors that prevent individuals from sifting linguistic grain from the chaff. Finnish higher education system and management schools were ranked substantially higher by the Global Economic Forum [49] in 2015. Out of 144 countries, Slovenian higher education system is ranked 48th (scoring 4.1 on a scale from one to seven), Finnish second (5.9), with Finnish management schools taking tenth place (5.6) and Slovenian 62nd (4.4).

Being teachers ourselves, we thought it would be interesting to see if there are any substantial differences in recognizing pseudo- 
profound statements between Slovenian and Finnish educators and students.

The review of literature on the topic under discussion showed that one may focus on bullshit product, bullshit producers and/or bullshit receivers. When focusing on the product of bullshitting there are roughly two kinds of bullshit for the researchers to deal with: 1 . bullshit with minor effects on bullshitees (such as the one found in marketing, conversations between friends and acquaintances, etc.) and 2. bullshit with dire consequence for bullshitees (in education systems at all levels, in academic discourse, in political discourse, consulting, etc.). When focusing on bullshit producers, the bullshitters are of the following types: 1. incompetent individuals who try to appear knowledgeable (ranging from charlatans to great pretenders in social sciences and those in between), 2. regurgitators parroting someone else's written or spoken discourse, 3. individuals with psychological difficulties. There is no need to point out that combinations of the above are possible and very likely. It seems reasonable to divide bullshitees with regard to their inability to recognize bullshit: 1 . individuals lacking the ability to engage in analytical reasoning, 2. individuals lacking the willingness to employ the effort required to figure out the meaning of discourse, 3. individuals lacking skepticism and critical thinking skills, and last but not least, 4. individuals with poor language skills. Again, many combinations are possible.

Our research proved that there is a negative correlation between the Need for Cognition and pseudo-profound statements for the whole sample. On the other hand, its is not statistically significant for the subsample of Finnish teachers and students, for the subsample of both Finnish and Slovenian students, where it is not present or statistically significant, and for the subsample of teachers (Slovenian and Finnish) where the correlation is negative, but not statistically significant. As for the Faith in Intuition and pseudo-profound statements, a positive correlation does not exist, except for the subsample of Slovenian and Finnish teachers. Finally, our research proved that the correlation between Need for Cognition and Faith in Intuition is strong, positive and statistically significant.

It is difficult to explain why our respondents judged pseudoprofound statements as meaningful. It could be hypothesized that the respondents, who were faced with the complexity of the chosen esoteric pseudo-profound statements, might not want to endure the struggle to grasp the meaning of the statements and simply rated vacuous statements as profound either due to the lack of motiva- 
tion to engage in cognitive activities or because they assumed, in a face-saving fashion, that the statements must have been somewhat meaningful. The results of our research also revealed that our respondents considered many pseudo-profound statements as substantially more profound than the two statements by Einstein (The significant problems we face today cannot be solved at the same level of thinking we were at when we created them.) and Sir Ken Robinson (Responding to works of art is also a creative process.). On the other hand, the statement by Voltaire's (Anything that is too stupid to be spoken is sung.), scored on average above 3.6, was recognized as highly profound by all groups of respondents (Finnish and Slovenian teachers and students). Nevertheless, the results of our study are far from being unexpected: both Slovenian and Finnish teachers are more likely to engage in cognitive activities than students and are less likely to trust intuition than students, and see profoundness in empty statements less often. Above all, our research revealed that both students and teachers from Slovenia and Finland need a better crap detector and that there are only minor differences between the two education systems as far as recognizing pseudo-profound statements is concerned.

We believe, even more so after we have conducted the study, that bullshit should be considered an important topic worth scientific research. After all, teachers should be 'committed to the task of earnestly searching for the truth' (Damer 2012) and be aware that there is no truth whatsoever in pseudo-profound statements. Thus, we must oppose and expose the pseudo-profound whenever possible, help students to recognize obscure and inflated language and teach them that it is right if we all do not suffer pseudo-profound discourse gladly.

References

Belfiore, E. 2009. 'On Bullshit in Cultural Policy Practice and Research: Notes from the British Case.' International Journal of Cultural Policy 15 (3): 343-59.

Bernal, S. 2006. 'Bullshit and Personality.' In Bullshit and Philosophy, edited by G. L. Hardcastle and G. A. Reisch, 63-82. Chicago: Open Court.

Billig, M. 2013. Learn to Write Badly: How to Succeed in the Social Sciences. Cambridge: Cambridge University Press.

Black, M. 2015. The Prevalence of Humbug and Other Essays. Ithaca, NY: Cornell University Press.

Buekens, F., and M. Boudry. 2015. 'The Dark Side of the Loon: Explaining the Temptations of Obscurantism.' Theoria 81 (2): 126-42. 
Cacioppo, J. T., and R. E. Petty. 1982. 'The Need for Cognition.' Journal of Personality and Social Psychology 42 (1): 116-31.

Cacioppo, J. T., R. E. Petty, and C. F. Kao. 1984. 'The Efficient Assessment of Need for Cognition.' Journal of Personality Assessment 48 (3): 3067.

Chomsky, N. 2002. Syntactic Structures. Berlin: Walter de Gruyter.

Chopra, D. 1993. Ageless Body, Timeless Mind: The Quantum Alternative to Growing Old. New York: Harmony.

Cohen, G. A. 2002. 'Deeper into Bullshit.' In Contours of Agency: Essays on Themes from Harry Frankfurt, edited by S. Buss and L. Overton, 321-39. Cambridge: мiт Press.

Čebron, N. 2002. 'Primerjava prevodov ustreznic termina "slika" v kitajščini, angleščini in slovenščini.' In Riječki filološki dani: zbornik radova s Međunarodnoga znanstvenog skupa Riječki filološki dani održanoga u Rijeci od 9. do 11. studenoga 20oo, edited by D. Stolac, 75-88. Rijeka: Filozofski fakultet.

Dalton, C. 2016. 'Bullshit for You; Transcendence for Me: A Commentary on "On the reception and detection of pseudo-profound bullshit."' Judgment and Decision Making 11 (1): 121-22.

Damer, T. E. 2012. Attacking Faulty Reasoning. Boston: Cengage Learning.

de Wall, C. 2006. 'The Importance of Being Earnest: A Pragmatic Approach to Bullshitting.' In Bullshit and Philosophy, edited by G. L. Hardcastle and G. A. Reisch, 99-113. Chicago: Open Court.

Epstein, S., R. Pacini, V. Denes-Raj, and H. Heier. 1996. 'Individual Differences in Intuitive-Experiential and Analytical-Rational Thinking Styles.' Journal of Personality and Social Psychology 71 (2): 390-405.

Eubanks, P., and J. D. Schaeffer. 2008. 'A Kind Word for Bullshit: The Problem of Academic Writing.' College Composition and Communication 59 (3): 372-88.

Evans, J. S., and K. E. Stanovich. 2013. 'Dual-Process Theories of Higher Cognition Advancing the Debate.' Perspectives on Psychological Science 8 (3): 223-41.

Frankfurt, H. G. 2005. On Bullshit. Princeton, NJ: Princeton University Press.

Giroux, H. A. 2013. The Violence of Organized Forgetting. San Francisco: City Lights Books.

Kahneman, D. 2011. Thinking, Fast and Slow. London: Macmillan.

Keller, J., G. Bohner, and H. P. Erb. 200o. 'Intuitive und heuristische Urteilsbildung-verschiedene Prozesse? Präsentation einer deutschen Fassung des "Rational-Experiential Inventory" sowie neuer Selbstberichtskalen zur Heuristiknutzung.' Zeitschrift für Sozialpsychologie 31 (2): 87-101.

Keysar, B., S. L. Hayakawa, and S. G. An. 2012. 'The Foreign-Language 
Effect Thinking in a Foreign Tongue Reduces Decision Biases.' Psychological Science 23 (6): 661-68.

Larivière, V., S. Haustein, and P. Mongeon. 2015. 'The Oligopoly of Academic Publishers in the Digital Era.' PloS One 10 (6): e0127502.

Maes, H., and K. Schaubroeck. 2006. 'Different Kinds and Aspects of Bullshit.' In Bullshit and Philosophy, edited by G. L. Hardcastle and G. A. Reisch, 171-83. Chicago: Open Court.

McGinn, C. 2008. Mindfucking. Stocksfield: Acumen.

Mittelstaedt, R. 2007. 'Book Review: On Bullshit; Harry G. Frankfurt.' Journal of Macromarketing 27 (2): 197-8.

Nielsen, R. K. 2015. 'Social Media and Bullshit.' Social Media and Society. https://doi.org/10.1177/2056305115580335

Olson, K., C. Camp, and D. Fuller. 1984. 'Curiosity and Need for Cognition.' Psychological Reports 54 (1): 71-74.

Orwell, G. 2013. Politics and the English Language. London: Penguin.

Oxford, R. L. 1990. Language Learning Strategies: What Every Teacher Should Know. New York: Newbury House.

Pfattheicher, S., and S. Schindler. 2016. 'Misperceiving Bullshit as Profound Is Associated with Favorable Views of Cruz, Rubio, Trump and Conservatism.' Plos One 11(4): e0153419.

Pennycook, G. 2016. 'Bullshit Detection and Cognitive Reflection.' https ://ssrn.com/abstract2749158

Pennycook, G., J. A. Cheyne, N. Barr, D. J. Koehler, and J. A. Fugelsang. 2015. 'On the Reception and Detection of Pseudo-Profound Bullshit.' Judgment and Decision Making 10 (6): 549-63.

- 2016. 'It's Still Bullshit: Reply to Dalton (2016).' Judgment and Decision Making 11 (1): 123-25.

Pinker, S. 2013. Language, Cognition, and Human Nature: Selected Articles. Oxford: Oxford University Press.

Postman, N. 1969. 'Bullshit and the Art of Crap-Detection.' Paper presented at annual convention of the National Council of Teachers of English, Washington, DC, September.

Quandt, R. E. 2007. 'On Wine Bullshit: Some New Software?' Journal of Wine Economics 2 (2): 129-35.

Richardson A. 2006. 'Performing Bullshit and the Post-Sincere Condition.' In Bullshit and Philosophy, edited by G. L. Hardcastle and G. A. Reisch, 83-98. Chicago: Open Court.

Sassoon, D. 2005. 'Bluff and Bull in Education.' Management in Education 19 (5): 32-33.

Selwyn, N. 2016. 'Minding our Language: Why Education and Technology is Full of Bullshit ... and What Might Be Done about it.' Learning, Media and Technology 41 (3): 437-43.

Smagorinsky, P., E. A. Daigle, C. O’Donnell-Allen, and S. Bynum. 2010. 'Bullshit in Academic Writing: A Protocol Analysis of a High School 
Senior's Process of Interpreting Much Ado About Nothing.' Research in the Teaching of English 44 (4): 368-405.

Sokal, A. 2008. Beyond the Hoax: Science, Philosophy and Culture. Oxford: Oxford University Press.

Sword, H. 2012. Stylish Academic Writing. Cambridge: Harvard University Press.

Šalamun, T. 1966. Poker. Ljubljana: Samizdat.

Tavakol, M., and R. Dennick. 2011. 'Making Sense of Cronbach's Alpha.' International Journal of Medical Education 2:53-55.

Tietge, D. J. 2006. Rhetoric is Not Bullshit: Bullshit and Philosophy. Chicago; LaSalle: Open Court.

Venkatraman, M. P., D. Marlino, F. R. Kardes, and K. B. Sklar. 1990. 'Effects of Individual Difference Variables on Responses to Factual and Evaluative Ads.' In Advances in Consumer Research, edited by M. E. Goldberg, G. Gorn, and R. W. Pollay, 17:761-65. Provo: Association for Consumer Research.

Venkatraman, M. P., and L. L. Price. 1990. 'Differentiating between Cognitive and Sensory Innovativeness: Concepts, Measurement, and Implications.' Journal of Business Research 20 (4): 293-315.

Wang, A. Y., and M. H. Newlin. 2000. 'Characteristics of Students Who Enroll and Succeed in Psychology Web-Based Classes.' Journal of Educational Psychology 92 (1): 137-43.

This paper is published under the terms of the Attribution-

NonCommercial-NoDerivatives 4.o International (CC BY-NC-ND 4.0)

License (http://creativecommons.org/licenses/by-nc-nd/4.o/). 